\title{
Sensorimotor Skill Learning in Amnesia: Additional Evidence for the Neural Basis of Nondeclarative Memory
}

\author{
Daniel Tranel, ${ }^{1}$ Antonio R. Damasio, Hanna Damasio, and Joan P. Brandt \\ Department of Neurology \\ Division of Behavioral Neurology and Cognitive Neuroscience \\ University of Iowa College of Medicine \\ Iowa City, Iowa 52242
}

\begin{abstract}
We investigated sensorimotor skill learning, a form of nondeclarative (implicit) memory, in 28 subjects with declarative (explicit) memory defects caused by either mesial temporal $(n=15)$ or basal forebrain $(n=13)$ damage and in 66 normal control subjects. All 28 amnesics had normal learning of a rotor pursuit task. We also studied in detail the sensorimotor skill learning of patient Boswell. As a result of bilateral damage to both mesial and lateral aspects of the temporal lobes and to the basal forebrain, Boswell has one of the most severe impairments ever reported for learning of all types of declarative knowledge. Compared to matched controls, Boswell acquired and retained normally the skills associated with performing motor tasks. We conducted a long-term (2-year) followup study of Boswell's retention of the rotor pursuit task, and we found that he retained the skill as well as normal controls.

Our study builds on previous work in the following respects: (1) It provides evidence, for the first time, that skill learning is normal in basal forebrain amnesics; (2) it shows that patient Boswell has normal learning and long-term retention of sensorimotor skills, in spite of his extensive damage; and (3) it offers additional evidence that mesial temporal lobe damage spares skill learning. These findings demonstrate unequivocally that sensorimotor skill learning does not require structures in mesial and lateral temporal regions nor in basal forebrain.

${ }^{1}$ Corresponding author.
\end{abstract}

\section{Introduction}

A number of investigations have established that the learning of new skills can be preserved in patients who are unable to learn new words, faces, and facts (e.g., Corkin 1965, 1968; Milner 1972; Cermak et al. 1973; Cohen and Squire 1980; Martone et al. 1984; Eslinger and Damasio 1986; Gabrieli et al. 1993; for reviews, see Baddeley 1982; Hintzman 1990; Shimamura 1990; Cohen and Eichenbaum 1993). The concepts of "declarative" and "nondeclarative" memory have been used to refer to the different types of information and task demands that are dissociated in such patients (Squire 1992). Declarative memory refers to representations of facts and events that can only be brought to mind in image form. Nondeclarative memory pertains to information that is not amenable to imagetic representation. Sensorimotor skills, which refer to the knowledge of how to perform a motor task, require nondeclarative memory. Only the factual information associated with the acquisition of the task requires declarative memory (Cohen and Squire 1980; Squire 1992). Another way to conceptualize this distinction is along a dimension of "explicit" and "implicit," where explicit corresponds to declarative and implicit corresponds to nondeclarative (e.g., Schacter 1987).

The dissociation between declarative and nondeclarative memory in brain-damaged patients has led to the proposal that the neural systems underlying the two types must be different (Eslinger and Damasio 1986; Damasio 1989; Damasio et al. 1989; Squire 1992; Petri and Mishkin 1994). There is evidence that the mesial temporal system, which includes the entorhinal and perirhinal cortices, hippocampus proper, parahippocampal gyrus, and amygdala and which is critical for the acquisition of declarative information, is not nec-

LEARNING \& MEMORY 1:165-179 (c) 1994 by Cold Spring Harbor Laboratory Press ISSN1072-0502/94 \$5.00

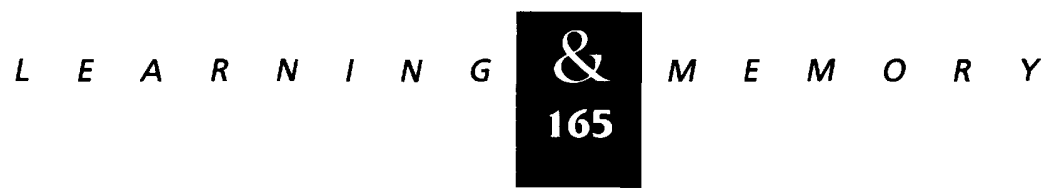


essary for skill learning. Damage to mesial temporal structures from surgical ablation (e.g., Milner 1972) or Alzheimer's disease (e.g., Eslinger and Damasio 1986; Gabrieli et al. 1993) does not pre. clude normal learning of motor skills. There is also evidence that medial diencephalic damage of the type associated with alcoholic Korsakoff's syndrome, which typically produces a severe amnesia for declarative material, is compatible with normal skill learning (Martone et al. 1984; for review, see Butters and Stuss 1989).

Moreover, the cerebellum and neostriatum, which are intact in the various patients cited above, have been implicated as crucial structures underlying acquisition of motor skills (McCormick and Thompson 1984; Eslinger and Damasio 1986; Thompson 1986; Saint-Cyr et al. 1988; Sanes et al. 1990; Seitz et al. 1990; Schmahmann 1991; Fiez et al. 1992; Grafman et al. 1992; Saint-Cyr and Taylor 1992; Heindel et al. 1993; Pascual-Leone et al. 1993), although not all studies have produced consistent findings (Daum et al. 1993). On the other hand, nothing is known about the possible contribution to skill learning, of structures such as the basal forebrain or the nonmesial temporal cortices, whose damage is known to compromise declarative memory (Damasio et al. 1985a,b, 1989).

In this paper we report an investigation of sensorimotor skill learning in 15 subjects with damage to the mesial temporal lobe and 13 with damage to basal forebrain. We also conducted a detailed investigation of patient Boswell, whose bilateral lesions to mesial and lateral temporal lobe as well as basal forebrain structures have produced one of the most profound anterograde and retrograde amnesic syndromes ever reported. The normal skill learning that we found in all subjects demonstrates unequivocally that sensorimotor skill learning does not require structures in mesial and lateral temporal regions nor in basal forebrain. The findings also support the notion that the brain honors a fundamental distinction between information that can only be recalled in imagetic form and information that can be recorded as a motor output.

\section{Materials and Methods}

\section{SUBJECTS}

The subjects for this study were selected from the Patient Registry of the University of Iowa's Di- vision of Behavioral Neurology and Cognitive Neuroscience. The criterion for selection was the presence of damage (unilateral or bilateral) in the mesial temporal region (entorhinal/perirhinal cortices, hippocampus, parahippocampal gyrus, and amygdala) or basal forebrain, as determined by our standard method of lesion analysis (Damasio and Damasio 1989; Damasio and Frank 1992). In addition, we conducted detailed studies of patient Boswell (see below).

\section{MESIAL TEMPORAL LOBE}

Fifteen subjects with mesial temporal lobe lesions were studied. The demographic information for this group is provided in the upper part of Table 1. Pertinent data regarding neuropsychological status are presented in the upper part of Table 2. These data were interpreted by one of us (D.T.) who was "blind" to details of the subjects' lesions, using standard normative information that takes into account age, gender, and estimated premorbid intelligence (Lezak 1983; Spreen and Strauss 1991; Tranel 1994). As the data in Table 2 indicate, the subjects have significant declarative memory impairments. In general, the memory defects show the expected pattern of material specificity; that is, subjects with left-sided lesions tended to have more impairment for verbally based material, and subjects with right-sided lesions tended to have more impairment for nonverbal, visuospatial material.

Details of the neuroanatomical status of these subjects are presented in the upper portion of Table 3 . All subjects have unilateral ( $\mathrm{six}$, left; seven, right) or bilateral $(n=2)$ mesial temporal damage, affecting all or parts of the entorhinal and perirhinal cortices, hippocampus, parahippocampal gyrus, and amygdala. Etiologic information is also provided in Table 3; most of the subjects had herpes simplex encephalitis, anoxia/ischemia, or temporal lobectomy.

\section{BASAL FOREBRAIN}

Thirteen subjects with presumed basal forebrain damage were studied. Demographic information for this group is provided in the lower portion of Table 1. Neuropsychological findings are presented in the lower part of Table 2 . As in the case of the temporal lobe subjects, the neuropsycho-

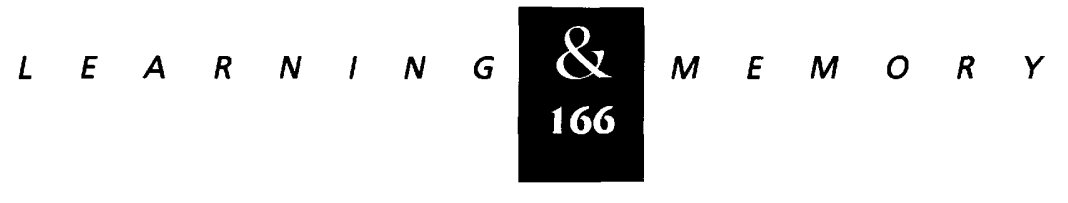


NEURAL BASIS OF NONDECLARATIVE MEMORY

Table 1: Demographic information

\begin{tabular}{|c|c|c|c|c|c|}
\hline Group & $\begin{array}{l}\text { Side of } \\
\text { lesion }^{\text {a }}\end{array}$ & Age/gender & Handedness ${ }^{b}$ & Education & Chronicity $^{c}$ \\
\hline \multicolumn{6}{|c|}{ Temporal lobe } \\
\hline LR-488 & $\mathrm{L}$ & $71 / F$ & +90 & 16 & 4 years \\
\hline LV-580 & L & $31 / F$ & +100 & 14 & 4 years \\
\hline $\mathrm{JM}-858$ & L & $41 / M$ & +100 & 16 & 6 years \\
\hline AN-1033 & $\mathrm{L}$ & $27 / M$ & +100 & 8 & 4 years \\
\hline UB-1251 & L & $35 / M$ & +100 & 12 & 4 years \\
\hline CS-1404 & L & $19 / M$ & +100 & 13 & 2 years \\
\hline MM-621 & $\mathrm{R}$ & $44 / M$ & +100 & 12 & 6 years \\
\hline LDV-692 & $\mathrm{R}$ & $20 / F$ & +100 & 12 & 3 years \\
\hline DM-727 & $\mathrm{R}$ & $37 / M$ & +100 & 12 & 3 years \\
\hline $\mathrm{RH}-747$ & $\mathrm{R}$ & $45 / M$ & +100 & 14 & 9 years \\
\hline TJ-1191 & $\mathrm{R}$ & $65 / M$ & +100 & 12 & 4 months \\
\hline MR-1323 & $\mathrm{R}$ & $71 / F$ & +100 & 10 & 2 years \\
\hline FR-1465 & $\mathrm{R}$ & $61 / M$ & +100 & 14 & 11 months \\
\hline $\mathrm{FDH}-1337$ & B & $40 / \mathrm{M}$ & +100 & 18 & 4 years \\
\hline RI-1746 & $\mathrm{B}$ & $26 / M$ & +100 & 12 & 7 months \\
\hline \multicolumn{6}{|c|}{ Basal forebrain } \\
\hline RF-297 & $\mathrm{L}$ & $38 / M$ & +100 & 16 & 7 years \\
\hline RG-1197 & $\mathrm{R}$ & $32 / \mathrm{M}$ & +100 & 16 & 10 years \\
\hline DM-1209 & $R$ & $38 / F$ & +60 & 12 & 1 year \\
\hline WM-415 & $\mathrm{B}$ & $49 / M$ & -70 & 11 & 2 years \\
\hline$M R-429$ & $\mathrm{~B}$ & $55 / F$ & +100 & 12 & 6 years \\
\hline$V Y-500$ & B & $58 / F$ & +100 & 12 & 5 years \\
\hline$S M-501$ & $\mathrm{~B}$ & $38 / \mathrm{M}$ & +100 & 12 & 15 months \\
\hline HS-1065 & B & $55 / F$ & +100 & 8 & 5 years \\
\hline FL-1164 & $\mathrm{B}$ & $75 / F$ & +100 & 12 & 5 years \\
\hline BY -1262 & B & $31 / \mathrm{F}$ & +100 & 14 & 2 years \\
\hline SB-1281 & $\mathrm{B}$ & $62 / \mathrm{F}$ & +20 & 12 & 3 years \\
\hline DM-1336 & $\mathrm{B}$ & $82 / \mathrm{M}$ & +100 & 9 & 12 years \\
\hline RS-1479 & B & $63 / F$ & +100 & 8 & 4 years \\
\hline
\end{tabular}

${ }^{\mathrm{a}}(\mathrm{L})$ Left; $(\mathrm{R})$ right; $(\mathrm{B})$ bilateral.

${ }^{b}$ Assessed with Geschwind-Oldfield Questionnaire, which ranges from +100 (full right-handedness) to - 100 (full left-handedness).

'Time elapsed between onset of lesion and collection of skill learning data.

logical data for basal forebrain subjects were interpreted in blind fashion, using standard norms. All subjects have significant declarative memory impairments.

The neuroanatomical status of the basal forebrain subjects is detailed in the lower portion of Table 3. Most ( 10 of 13) had suffered ruptures of aneurysms in the anterior communicating or anterior cerebral artery. These subjects have surgical clips (many of which are ferromagnetic), and for this reason they cannot be scanned with magnetic resonance (e.g., Klucznik et al. 1993), and their CT scans often have artifacts. As a consequence, the anatomical analysis of the images obtained in these subjects may be less than optimal. We selected subjects in whom basal forebrain damage could be established with a reasonable degree of confidence on the basis of neuroimaging information and neurosurgical reports.

PATIENT BOSWELL

Patient Boswell is a 65-year-old right-handed man who developed a severe amnesic syndrome

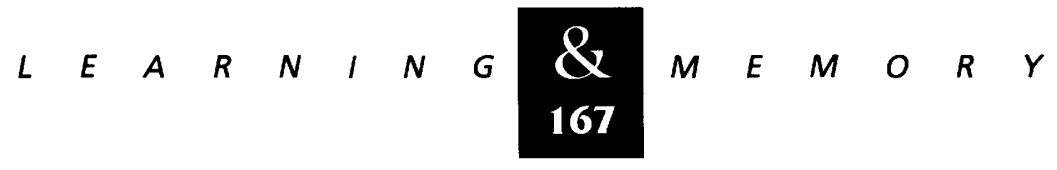


Tranel et al.

Table 2: Neuropsychological data

\begin{tabular}{|c|c|c|c|c|c|c|c|c|c|}
\hline \multirow[b]{2}{*}{ Group } & \multirow[b]{2}{*}{$\mathrm{VIQ}^{\mathrm{a}}$} & \multirow[b]{2}{*}{$\mathrm{PIQ}^{\mathrm{a}}$} & \multirow[b]{2}{*}{$M Q^{b}$} & \multicolumn{3}{|c|}{$A V L T^{c}$} & \multicolumn{2}{|c|}{$\mathrm{BVRT}^{\mathrm{d}}$} & \multirow[b]{2}{*}{ CFT-R } \\
\hline & & & & 1 & 5 & DR & $\mathrm{C}$ & $E$ & \\
\hline \multicolumn{10}{|c|}{ Temporal lobe } \\
\hline LR-488 & 100 & 97 & 90 & $\underline{3}$ & $\underline{4}$ & $\underline{2}$ & 7 & 4 & $\underline{16}$ \\
\hline LV-580 & $\underline{81}$ & 112 & $\underline{80 r}$ & $\underline{4}$ & $\underline{11}$ & 12 & 8 & 3 & 23 \\
\hline$J M-858$ & 106 & 117 & $\underline{92 r}$ & 6 & 11 & $\underline{3}$ & 7 & $\underline{4}$ & 25 \\
\hline AN-1033 & $\underline{77}$ & 101 & $\underline{68}$ & $\underline{4}$ & $\underline{6}$ & $\underline{0}$ & 9 & $\overline{1}$ & 19 \\
\hline UB-1251 & $\overline{93}$ & 99 & $\overline{97}$ & $\underline{2}$ & $\underline{4}$ & 1 & 7 & $\underline{6}$ & 25 \\
\hline CS-1404 & 114 & 108 & 105 & $\underline{4}$ & $\underline{11}$ & $\underline{5}$ & 9 & $\overline{1}$ & 30 \\
\hline$M M-621$ & 94 & 97 & 90 & 6 & $\underline{6}$ & $\underline{3}$ & $\underline{4}$ & 12 & $\underline{17}$ \\
\hline LDV-692 & 87 & $\underline{77}$ & 86 & 6 & 11 & $\underline{7}$ & $\underline{3}$ & 14 & $\underline{14}$ \\
\hline DM-727 & 109 & 119 & 112 & $\underline{5}$ & 14 & 11 & $\underline{6}$ & $\underline{5}$ & $\underline{17}$ \\
\hline $\mathrm{RH}-747$ & 103 & $\underline{86}$ & 116 & 10 & 13 & 13 & $\underline{5}$ & $\underline{8}$ & 28 \\
\hline TJ-1191 & 91 & $\overline{75}$ & 108 & $\underline{3}$ & $\underline{10}$ & $\underline{6}$ & $\underline{0}$ & $\underline{2 \overline{3}}$ & $\underline{2}$ \\
\hline MR-1323 & 91 & $\underline{76}$ & 85 & 6 & $\underline{9}$ & $\underline{3}$ & $\underline{4}$ & 10 & $\underline{13}$ \\
\hline FR-1465 & 110 & 118 & $\underline{87 r}$ & $\underline{5}$ & $\underline{9}$ & $\underline{6}$ & $\underline{5}$ & $\underline{8}$ & $\underline{12}$ \\
\hline FDH-1337 & 112 & 109 & $\underline{83 r}$ & 6 & $\underline{7}$ & $\underline{0}$ & 7 & $\underline{5}$ & $\underline{6}$ \\
\hline RI-1746 & 95 & 105 & $\underline{69 r}$ & $\underline{5}$ & 7 & $\underline{4}$ & $\underline{6}$ & $\underline{6}$ & $\underline{6}$ \\
\hline \multicolumn{10}{|c|}{ Basal forebrain } \\
\hline RF-297 & 110 & $\underline{97}$ & $\underline{86}$ & $\underline{5}$ & $\underline{9}$ & $\underline{2}$ & 7 & $\underline{5}$ & $\underline{12}$ \\
\hline RG-1197 & 113 & 114 & 115 & 7 & $\underline{11}$ & 9 & 9 & 1 & $\underline{12}$ \\
\hline DM-1209 & 93 & 94 & 88 & $\underline{5}$ & 13 & 10 & $\underline{2}$ & $\underline{10}$ & $\underline{8}$ \\
\hline WM-415 & 101 & $\underline{81}$ & $\underline{63}$ & $\underline{2}$ & $\underline{5}$ & 1 & $\underline{3}$ & 11 & $\underline{3}$ \\
\hline MR-429 & 84 & $\overline{81}$ & $\overline{87}$ & $\underline{3}$ & $\underline{5}$ & 1 & $\underline{3}$ & 15 & $\underline{0}$ \\
\hline$V Y-500$ & 113 & $\underline{88}$ & $\underline{90 r}$ & 6 & $\underline{10}$ & $\underline{0}$ & $\underline{5}$ & $\underline{8}$ & $\underline{5}$ \\
\hline$S M-501$ & 82 & 84 & $\underline{74}$ & $\underline{3}$ & $\underline{8}$ & $\underline{4}$ & $\underline{4}$ & $\underline{10}$ & $\underline{6}$ \\
\hline HS-1065 & 82 & 86 & 82 & $\underline{4}$ & 12 & 8 & $\underline{4}$ & $\underline{9}$ & $\underline{15}$ \\
\hline FL-1164 & 97 & 90 & $\underline{57 r}$ & $\underline{4}$ & $\underline{3}$ & $\underline{2}$ & 5 & 7 & 10 \\
\hline BY-1262 & 80 & 83 & $\overline{82}$ & $\overline{5}$ & $1 \overline{1}$ & $\overline{8}$ & $\underline{6}$ & $\underline{8}$ & $\overline{13}$ \\
\hline SB-1281 & 90 & 70 & 59 & $\underline{2}$ & $\underline{4}$ & $\underline{0}$ & $\frac{1}{0}$ & $\frac{20}{17}$ & $\underline{0}$ \\
\hline DM-1336 & 114 & $\underline{103}$ & $1 \overline{14}$ & $\underline{3}$ & $\underline{5}$ & $\underline{\overline{6}}$ & $\underline{2}$ & 17 & $\overline{6}$ \\
\hline RS-1479 & 87 & 88 & $95 r$ & 5 & $\underline{7}$ & $\underline{8}$ & 5 & 7 & 18 \\
\hline
\end{tabular}

Underlined scores are defective (see text for details).

a(VIQ) Verbal I.Q.; (PIQ) performance I.Q. (from the WAIS-R).

${ }^{b}(M Q)$ A memory quotient prorated from the Wechsler Memory Scale, administered without the Visual Reproduction subtest, i.e., the score is derived from verbally based subtests only. MQs accompanied by an $r$ are the Verbal Index from the Wechsler Memory Scale-Revised.

${ }^{c}(A V L T)$ Auditory-Verbal Learning Test. Scores (\#/15) are for trial 1 (1), trial 5 (5), and 30-min delayed recall (DR).

d(BVRT) Benton Visual Retention Test. (C) Number correct (\#/10); (E) number of errors.

${ }^{e}(C F T-R)$ Complex Figure Test-Recall. The score $(\# / 36)$ is the 30 -min delayed recall.

following herpes simplex encephalitis in 1975. Details of his condition are available in other publications (Damasio et al. 1985b, 1987, 1989; Tranel and Damasio 1993). For the purposes of the present report, it is important to indicate that
Boswell has a severe inability to acquire virtually all forms of declarative information, such as facts, words, faces, and events. His memory for such information is in the range of $40 \mathrm{sec}$, and beyond this period, he does not appear to retain any trace of

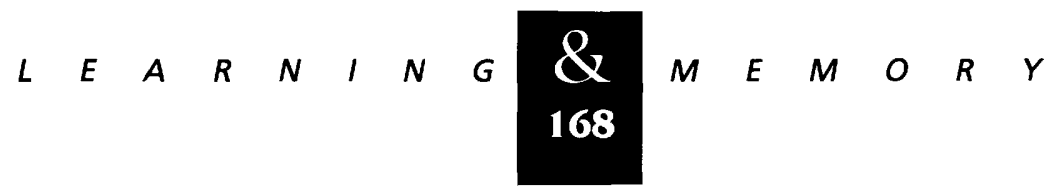


NEURAL BASIS OF NONDECLARATIVE MEMORY

Table 3: Neuroanatomical findings

\begin{tabular}{llll}
\hline & Side & Etiology & Structures damaged \\
\hline $\begin{array}{l}\text { Temporal lobe } \\
\text { LR-488 }\end{array}$ & L & HSE & mesial and anterolateral temporal \\
LV-580 & L & TL & mesial and anterolateral temporal \\
JM-858 & L & CVA & mesial occipitotemporal \\
AN-1033 & L & CHI & anterolateral and mesial temporal \\
UB-1251 & L & TL & mesial and anterolateral temporal \\
CS-1404 & L & TL & mesial and anterolateral temporal \\
MM-621 & R & TL & mesial and anterolateral temporal \\
LDV-692 & R & HSE & mesial, anterolateral, lateral temporal \\
DM-727 & R & CVA & mesial and anterolateral temporal \\
RH-747 & R & CVA & mesial temporal; inferior parietal \\
TJ-1191 & R & CVA & mesial temporal; inferior parietal \\
MR-1323 & R & CVA & mesial temporal \\
FR-1465 & R & HSE & mesial, anterolateral, inferior temporal \\
FDH-1337 & B & A/I & bilateral hippocampus \\
RI-1746 & B & A / & bilateral hippocampus \\
Basal forebrain & & & \\
RF-297 & L & ACoA & basal forebrain \\
RG-1197 & R & CVA & ventromedial frontal; basal forebrain \\
DM-1209 & R & ACoA & basal forebrain \\
WM-415 & B & ACoA & basal forebrain; orbitofrontal \\
MR-429 & B & ACoA & basal forebrain; ventromedial frontal \\
VY-500 & B & ACoA & basal forebrain; anterior cingulate \\
SM-501 & B & ACoA & basal forebrain \\
HS-1065 & B & ACoA & basal forebrain; ventromedial frontal \\
FL-1164 & B & CVA & ventromedial frontal; basal forebrain \\
BY-1262 & B & CVA & ventromedial frontal; basal forebrain; right parietal \\
SB-1281 & B & ACoA & basal forebrain \\
DM-1336 & B & ACoA & ventromedial frontal; basal forebrain \\
RS-1479 & B & ACoA & basal forebrain \\
\hline
\end{tabular}

a(HSE) Herpes simplex encephalitis; (TL) temporal lobectomy; (CVA) cerebrovascular accident; (CHI) closed head injury; (A/I) anoxia/ischemia; (ACoA) anterior communicating artery aneurysm.

new information. His neuroanatomical status is as follows. He has lost the entire mesial component of the temporal lobes, bilaterally, including entorhinal and perirhinal cortices, the hippocampus proper, and the amygdala. Most of the anterolateral temporal lobes are also destroyed bilaterally (cytoarchitectonic areas 38, 20/21, and most of area 37). The anterior insula is damaged bilaterally, as are the posterior ventromedial frontal cortices and basal forebrain region. There is also some damage to the anterior cingulate gyrus. Of most relevance here, Boswell has both mesial and lateral temporal lobe damage, and damage to basal forebrain; he has one of the most severe anterograde and retrograde amnesic syndromes ever reported.
CONTROL SUBJECTS

Two groups of normal control subjects participated in the rotor pursuit experiment described below. The first ("group" control: G-CON) comprised 60 subjects who have participated in a series of normative studies in our laboratory, including the rotor pursuit task. The group is divided into three age brackets, each containing 20 subjects ( 10 men and 10 women): 20-39, 40-59, and $60+$. The second control group ("Boswell" control: B-CON), matched specifically to patient Boswell on age and educational level, comprised six neurologically healthy volunteers (three men, three women) recruited from the local commu- 
nity. Another criterion for members of this control group was availability for long-term followup (see below). The six B-CON subjects had an average age of 65.1 (S.D. $=4.6$ ) and an average education of 13.8 years $($ s.D. $=3.6)$. All six were right-handed.

In the rotor pursuit contrasts below, the temporal lobe and basal forebrain subjects were compared to subjects from the appropriate age bracket in the G-CON group. Boswell was compared to his own control group (B-CON).

\section{PROCEDURES FOR ALL SUBJECTS}

\section{ROTOR PURSUIT}

The rotor pursuit task had two phases: (1) the learning phase, which consisted of five consecutive learning trials; and (2) the short-term delay phase, which consisted of two trials, conducted 20 min after completion of the learning phase. To perform the task, subjects held the stylus of the apparatus (Lafayette Instrument Company, model 30011 ) in their right hands, rested it on a small metal target, and tried to maintain contact with the target as it rotated. A stop clock recorded time on target (TOT), which is the total time per trial that the subject maintained contact between the stylus and target. The speed of rotation was set at $30 \mathrm{rpm}$.

\section{PROCEDURES FOR PATIENT BOSWELL}

ROTOR PURSUIT

Boswell and the B-CON subjects were studied with the rotor pursuit procedure as described above, except that an additional dependent measure was recorded, number of impulses (NOI), which refers to the number of times per trial that the subject loses contact between the stylus and the target. Two years after initial learning, Boswell and the B-CON subjects were administered a longterm delay phase, which consisted of two trials of performing the task. We also obtained responses from Boswell and the B-CON subjects to a brief questionnaire that asked for factual information regarding the subject's memory of the task and procedure. The questionnaire, administered immediately prior to each of the delay phases before the subject had seen the apparatus again, asked the subject (1) whether she/he recalled the nature of the motor learning experiment completed $20 \mathrm{~min}$ (or 2 years) previously and (2) how the apparatus worked. Responses were scored on a three-point scale, with two points for detailed recall, one point for correct but incomplete information, and zero points for no recall. Thus, the maximum possible score on the factual recall questionnaire was four.

MIRROR TRACING

The mirror tracing task followed the conventional procedure (e.g., Milner 1962), in which the subject is required to trace the design of a figure, keeping inside two closely spaced borders. The subject is prevented from viewing his/her hand and the figure directly and can observe the performance only in a mirror reflection. To make the task challenging but not unduly difficult, we had Boswell trace a triangle with his right hand and a circle with his left hand. (We did not study control subjects with this task, and Boswell's results were analyzed qualitatively, in terms of whether there was evidence of a learning curve and retention of the skill over time.)

On each trial, Boswell was given a pencil and instructed to trace the design beginning at a specific starting point (the top of the figure). He was told to go as fast as possible but not to go outside the boundaries. The time taken to complete the tracing was recorded and constituted the dependent variable for this task. We did not record errors (which were minimal) but monitored performance continuously and gave frequent reminders to stay within the borders. Three trials were conducted, for each hand, on each of three consecutive days. Forty-eight hours after the third day (i.e., on day 5), three additional trials were conducted.

\section{MIRROR READING}

Stimuli We also administered to Boswell a mirror reading task. The task was modeled after the procedure used by Martone et al. (1984), which was adapted from the task described initially by Cohen and Squire (1980). The stimuli were $\mathbf{4 8 0}$ three- to five-letter words, selected to have a high frequency of the letters $b, d, u, n, p, q$, and $g$ (letters easily confused with one another in mirror image). Three words (comprising a "word triad") without obvious semantic associations were typed in lowercase letters, separated by a hyphen, on an index card. One hundred and sixty such cards were prepared in this fashion, and a black-and-white slide was made from each card. The slides were inserted into a carousel slide tray so that when projected, each word would appear as its mirror image.

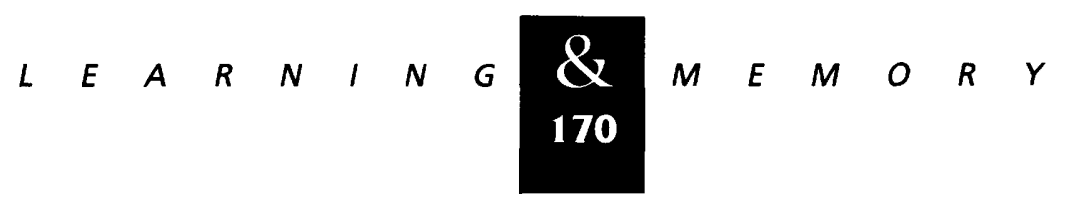


Procedure Boswell was shown a set of 60 word triads on each of 5 days, the first four consecutive and the final, $48 \mathrm{hr}$ after day 4 (i.e., a 48-hr delay). On each day, three blocks of 20 triads were presented. Ten-word triads were unique to each block (Unique), and 10 were common to all blocks across the $\mathbf{5}$ days (Repeated). Thus, in the first block of the first day, all triads were new, but thereafter, half the triads in any particular block had been seen previously and half had not. In each block of 20 triads, the unique and repeated triads were ordered randomly.

Boswell was instructed that he would be learning to "mirror read". He was told that three words at a time would appear as mirror images on the screen in front of him and that he should try to read the words in any order he liked. For each triad, the time taken to read all three words was measured with a stop clock and recorded. Mispronounced words were counted as correct, provided that all letters in the word were pronounced accurately. Otherwise, the experimenter notified Boswell immediately if he made an error, and timing was continued while Boswell was instructed to "try again". Boswell was allowed up to $4 \mathrm{~min}$ to read all three words, but the maximum time scored for any particular triad was $120 \mathrm{sec}$.

Immediately after the third test block on day 6 (i.e., the fifth and final mirror reading session), Boswell was given a recognition memory test for words used during the mirror reading task. This test consisted of a list of 60 typewritten words, 30 of which had been used during the mirror reading experiment and 30 of which were novel. Of the 30 mirror reading items, 15 were Unique and 15 were Repeated (selection was random for each type). Boswell was instructed to circle all the words that he could remember having seen during the mirror reading task.

\section{Results}

TEMPORAL LOBE AND BASAL FOREBRAIN AMNESICS

To facilitate comparisons to controls, the rotor pursuit data for these subjects were quantified as follows: For each subject, a percentage score was calculated for each trial after trial 1 . This score comprised the trial $n$ score, divided by the trial 1 score, multiplied by 100 . Thus, the scores for trials 2-5 and the delay trial (the latter being an average of two delay trials ) are percentages of the trial 1 score, for each subject. Percentages $>100$ indicate improvement relative to trial 1 . The same quantification procedure was followed for the $60 \mathrm{G}-\mathrm{CON}$ subjects.

Results for the TOT measure from the rotor pursuit task are presented in Tables 4 (temporal lobe amnesics) and 5 (basal forebrain amnesics). In each table, the means and standard deviations for the G-CON subjects are presented, broken down according to age bracket. Results for the amnesic subjects are also separated according to the age of the subjects, to facilitate comparisons with the relevant control data. All results are collapsed across gender, because we found that this factor did not affect skill learning performance in either the control or amnesic subjects.

We analyzed the data in Tables 4 and 5 with ANOVAs. Specifically, for each of the three age brackets and for each of the amnesic groups, a $2 \times 5$ ANOVA was conducted, using group (amnesic vs. control) as a between-subjects factor and trials (2-5 and delay) as a within-subjects factor. Six ANOVAs in all were conducted (we did not $\alpha$-correct these, given the direction of the outcomes). For each age bracket in Tables 4 and 5 , there was a main effect of trials, indicating that all groups improved consistently across learning trials. For Table 4 (temporal lobe amnesics) the trials values for the younger, middle, and older age brackets were $F(4,125)=5.24, \quad P<0.001$; $F(4,110)=3.63, \quad P<0.01 ; \quad F(4,110)=10.37$, $P<0.001$. For Table 5 (basal forebrain amnesics) the same respective trials values were $F(4,115)=4.15, \quad P<0.005 ; \quad F(1,110)=4.49$, $P<0.005 ; F(1,110)=11.08, P<0.001$. There was also a main effect of Group in the younger age bracket of Table $4[F(1,125)=18.43, P<0.001]$, reflecting the fact that the younger temporal lobe amnesics actually outperformed the controls. All other comparisons were nonsignificant, and in particular, there were no significant interactions. In fact, the group means and individual scores for the amnesic subjects were in nearly all cases at or above the levels of the controls.

\section{PATIENT BOSWELL AND THE B-CONTROLS}

ROTOR PURSUIT

Results for patient Boswell and the six B-CONs are depicted in Figures 1 (TOT) and 2

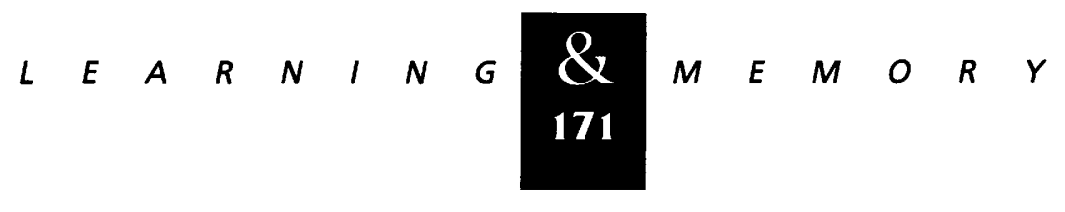


Tranel et al.

Table 4: Rotor pursuit learning: temporal lobe amnesics (TOT)

\begin{tabular}{|c|c|c|c|c|c|}
\hline \multirow[b]{2}{*}{ Age bracket } & \multicolumn{5}{|c|}{ Trial } \\
\hline & 2 & 3 & 4 & 5 & delay \\
\hline \multicolumn{6}{|l|}{$20-39$} \\
\hline Mean & 117.7 & 125.2 & 126.2 & 136.4 & 145.4 \\
\hline (S.D.) & $(13.7)$ & $(24.5)$ & $(32.1)$ & (38.3) & (34.3) \\
\hline LV-580 & 113 & 130 & 140 & 141 & 145 \\
\hline AN-1033 & 130 & 131 & 137 & 139 & 140 \\
\hline UB-1251 & 116 & 160 & 158 & 178 & 184 \\
\hline CS-1404 & 133 & 189 & 181 & 209 & 237 \\
\hline LDV -692 & 111 & 185 & 247 & 255 & 207 \\
\hline DM-727 & 114 & 140 & 138 & 152 & 153 \\
\hline RI-1746 & $\underline{114}$ & 115 & 129 & $\underline{158}$ & $\underline{160}$ \\
\hline Group mean & $\overline{118.7}$ & $\overline{150.0}$ & $\overline{161.4}$ & $\overline{176.0}$ & $\overline{175.1}$ \\
\hline (S.D.) & (8.9) & $(28.7)$ & $(41.6)$ & $(42.5)$ & $(36.0)$ \\
\hline \multicolumn{6}{|l|}{$40-59$} \\
\hline Mean & 138.6 & 143.5 & 158.6 & 165.8 & 178.8 \\
\hline (S.D.) & $(31.0)$ & $(37.0)$ & $(46.7)$ & $(47.7)$ & $(50.8)$ \\
\hline JM-858 & 144 & 164 & 178 & 193 & 196 \\
\hline$M M-621$ & 131 & 163 & 167 & 170 & 175 \\
\hline $\mathrm{RH}-747$ & 142 & 152 & 167 & 165 & 180 \\
\hline FDH-1337 & $\underline{128}$ & $\underline{145}$ & 143 & 143 & 153 \\
\hline Group mean & $\overline{136.3}$ & $\overline{156.0}$ & $\overline{163.8}$ & $\overline{167.8}$ & $\overline{176.0}$ \\
\hline (S.D.) & (7.9) & (9.1) & (14.8) & (20.5) & (17.8) \\
\hline \multicolumn{6}{|l|}{$60+$} \\
\hline Mean & 132.9 & 149.8 & 153.1 & 174.3 & 223.3 \\
\hline (S.D.) & $(21.0)$ & (33.0) & $(55.2)$ & $(60.6)$ & $(80.3)$ \\
\hline LR-488 & 144 & 154 & 159 & 177 & 198 \\
\hline TJ-1191 & 130 & 150 & 161 & 202 & 226 \\
\hline MR-1323 & 121 & 240 & 303 & 337 & 348 \\
\hline FR-1465 & 104 & 144 & 144 & $\underline{185}$ & 206 \\
\hline Group mean & $\overline{124.8}$ & $\overline{172.0}$ & $\overline{191.8}$ & $\overline{225.3}$ & $\overline{244.5}$ \\
\hline$(S . D)$. & (16.8) & $(45.5)$ & (74.6) & $(75.2)$ & $(70.0)$ \\
\hline
\end{tabular}

(NOI). For TOT, higher scores are better; for NOI, lower scores are better. The figures illustrate the following conclusions: First, the curves for Boswell and the controls are similar, for both dependent measures. Second, on every trial and for both dependent measures, Boswell's score is at or superior to the average of the controls. Third, Boswell's similarity to controls extends to both the 20-min- and 2-year-delay epochs. In sum, the data indicate that Boswell acquired and retained this motor skill at the same level as the controls, even after a 2-year delay.

To explore the degree of "forgetting" on this task, we conducted a $t$-test comparing the level of performance on trial 5 with the level on the 2-year delay trial. The outcome was nonsignificant both with $[T(12)=1.93, P>0.075]$ and without $[T(10)=1.80, P>0.10]$ the inclusion of Boswell in the group, suggesting that the decline in performance between trial 5 and the 2-year delay did not represent a significant amount of forgetting.

On the factual information questionnaire pertaining to the rotor pursuit experiment, the control subjects (B-CON) demonstrated the expected high levels of retention of knowledge regarding the task and procedures. At the 20-min-delay ep-

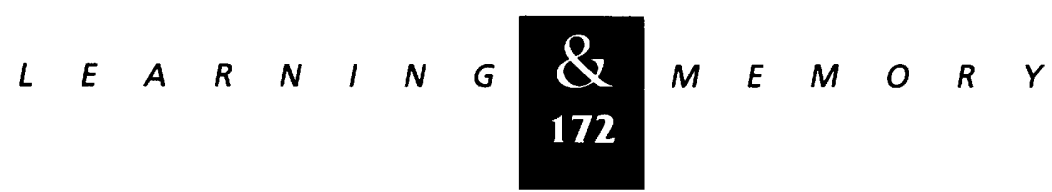


Table 5: Rotor pursuit learning: Basal forebrain amnesics (TOT)

\begin{tabular}{|c|c|c|c|c|c|}
\hline \multirow[b]{2}{*}{ Age bracket } & \multicolumn{5}{|c|}{ Trial } \\
\hline & 2 & 3 & 4 & 5 & delay \\
\hline \multicolumn{6}{|l|}{$20-39$} \\
\hline $\begin{array}{l}\text { Mean } \\
\text { (S.D.) }\end{array}$ & $\begin{array}{l}\mathbf{1 1 7 . 4} \\
(13.7)\end{array}$ & $\begin{array}{c}\mathbf{1 2 5 . 2} \\
(24.5)\end{array}$ & $\begin{array}{c}\mathbf{1 2 6 . 2} \\
(32.1)\end{array}$ & $\begin{array}{c}\mathbf{1 3 6 . 4} \\
(38.3)\end{array}$ & $\begin{array}{r}\mathbf{1 4 5 . 4} \\
(34.3)\end{array}$ \\
\hline RF-297 & 93 & 98 & 112 & 117 & 125 \\
\hline RG-1191 & 135 & 141 & 147 & 149 & 160 \\
\hline DM-1209 & 116 & 116 & 153 & 148 & 148 \\
\hline SM-501 & 103 & 133 & 148 & 155 & 160 \\
\hline BY-1262 & $\underline{122}$ & 143 & $\underline{161}$ & $\underline{162}$ & $\underline{166}$ \\
\hline $\begin{array}{l}\text { Group mean } \\
\text { (S.D.) }\end{array}$ & $\begin{array}{l}\mathbf{1 1 3 . 8} \\
(16.4)\end{array}$ & $\begin{array}{c}\mathbf{1 2 6 . 2} \\
(19.0)\end{array}$ & $\begin{array}{c}\mathbf{1 4 4 . 2} \\
(18.8)\end{array}$ & $\begin{array}{c}\mathbf{1 4 6 . 2} \\
(17.3)\end{array}$ & $\begin{array}{c}\mathbf{1 5 1 . 8} \\
(16.3)\end{array}$ \\
\hline \multicolumn{6}{|l|}{$40-59$} \\
\hline $\begin{array}{l}\text { Mean } \\
(S . D .)\end{array}$ & $\begin{array}{c}\mathbf{1 3 8 . 6} \\
(31.0)\end{array}$ & $\begin{array}{c}\mathbf{1 4 3 . 5} \\
(37.0)\end{array}$ & $\begin{array}{c}\mathbf{1 5 8 . 6} \\
(46.7)\end{array}$ & $\begin{array}{l}\mathbf{1 6 5 . 8} \\
(47.7)\end{array}$ & $\begin{array}{c}\mathbf{1 7 8 . 8} \\
(50.8)\end{array}$ \\
\hline WM-415 & 131 & 146 & 171 & 163 & 186 \\
\hline MR-429 & 121 & 125 & 124 & 198 & 224 \\
\hline VY-500 & 147 & 194 & 147 & 169 & 212 \\
\hline HS-1065 & $\underline{135}$ & $\underline{139}$ & $\underline{158}$ & $\underline{169}$ & $\underline{188}$ \\
\hline $\begin{array}{l}\text { Group mean } \\
\text { (S.D.) }\end{array}$ & $\begin{array}{c}\mathbf{1 3 3 . 5} \\
(10.8)\end{array}$ & $\begin{array}{l}\mathbf{1 5 1 . 0} \\
(30.0)\end{array}$ & $\begin{array}{l}\mathbf{1 5 0 . 0} \\
(19.9)\end{array}$ & $\begin{array}{r}\mathbf{1 7 4 . 8} \\
(15.8)\end{array}$ & $\begin{array}{r}\mathbf{2 0 2 . 5} \\
(18.6)\end{array}$ \\
\hline \multicolumn{6}{|l|}{$60+$} \\
\hline $\begin{array}{l}\text { Mean } \\
\text { (S.D.) }\end{array}$ & $\begin{array}{c}\mathbf{1 3 2 . 9} \\
(21.0)\end{array}$ & $\begin{array}{c}\mathbf{1 4 9 . 8} \\
(33.0)\end{array}$ & $\begin{array}{c}\mathbf{1 5 3 . 1} \\
(55.2)\end{array}$ & $\begin{array}{r}174.3 \\
(60.6)\end{array}$ & $\begin{array}{r}\mathbf{2 2 3 . 3} \\
(80.3)\end{array}$ \\
\hline FL-1164 & 142 & 149 & 161 & 191 & 191 \\
\hline SB-1281 & 103 & 125 & 169 & 200 & 206 \\
\hline DM-1336 & 113 & 108 & 119 & 148 & 199 \\
\hline RS-1479 & $\underline{133}$ & $\underline{163}$ & $\underline{166}$ & $\underline{181}$ & $\underline{236}$ \\
\hline $\begin{array}{l}\text { Group mean } \\
\text { (S.D.) }\end{array}$ & $\begin{array}{l}\mathbf{1 2 2 . 8} \\
(17.9)\end{array}$ & $\begin{array}{c}\mathbf{1 3 6 . 3} \\
(24.5)\end{array}$ & $\begin{array}{c}\mathbf{1 5 3 . 8} \\
(23.4)\end{array}$ & $\begin{array}{c}\mathbf{1 8 0 . 0} \\
(22.7)\end{array}$ & $\begin{array}{r}\mathbf{2 0 8 . 0} \\
(19.6)\end{array}$ \\
\hline
\end{tabular}

och, all six controls obtained maximum scores of 4 out of $4(X=4$, S.D. $=0)$, and at the 2-year delay, five of six controls again obtained maximum scores, with one subject scoring 3 out of 4 $(X=3.8$, S.D. $=0.4)$. Most of the controls recalled more about the situation than specifically requested in the questionnaire-for example, details about the experimenter, other procedures that had been administered at the same time. Boswell, as expected, given his severe amnesia for declarative knowledge, never indicated that he recognized in any way the task and procedures. His scores on the factual questionnaire were 0 out of 4 at both followup epochs.
MIRROR TRACING

Boswell's results on the mirror tracing task are presented in Figures 3 (right hand) and 4 (left hand). The latency data were subjected to a base10 logarithmic transformation, to reduce the highly skewed distribution of the raw data (especially on the first few trials) and simplify data presentation. ${ }^{1}$ The pattern of results is similar for both hands. Boswell showed improved latencies across

\footnotetext{
${ }^{1}$ This type of data transformation has been used by other investigators with similiar paradigms and dependent measures (e.g., Martone et al. 1984).
} 
ROTOR PURSUIT

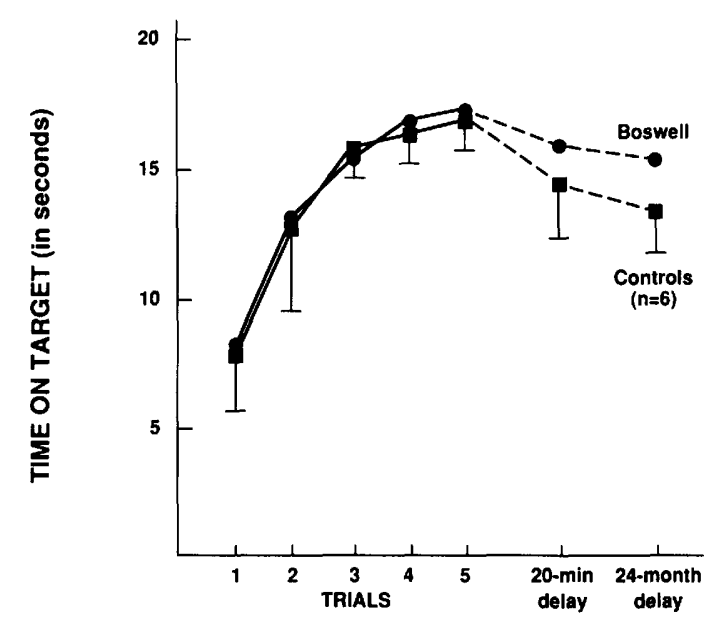

Figure 1: Time-on-target (TOT) scores on the rotor pursuit task for Boswell and matched controls (B-CON) as a function of trial. Boswell performed at the same level as the controls at every trial point, including the short (20$\mathrm{min}$ ) and long (24-months) delays. (Error bars indicate standard error of the mean.)

the first 3 days of the task, with steady reductions in the time needed to complete the mirror tracings across days 1, 2, and 3. Following a 48-hour delay (Day 5 ), he demonstrated substantial reten-

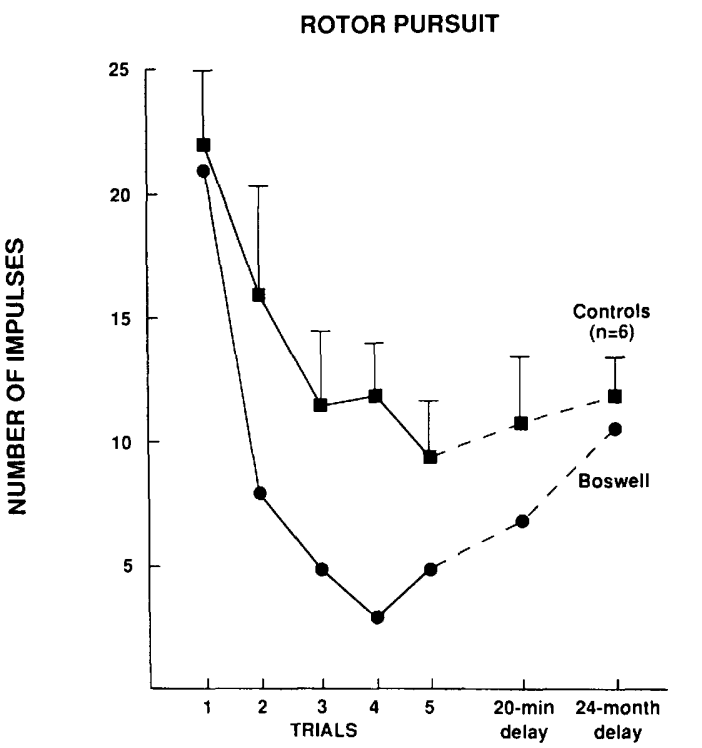

Figure 2: Number-of-impulse (NOI) scores on the rotor pursuit task for Boswell and matched controls (B-CON) as a function of trial. Boswell had scores that are equal to or better than the controls at every trial point, including the short (20-min) and long (24-month) delays. (Error bars indicate standard error of the mean.)

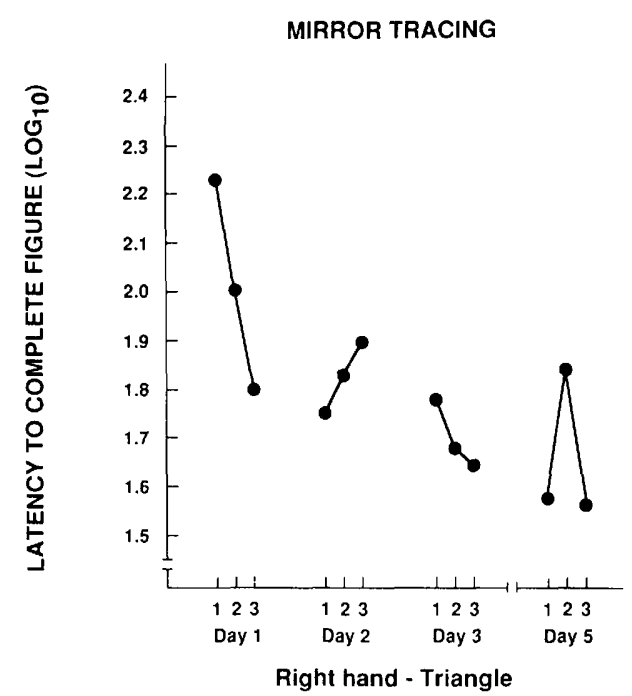

Figure 3: Boswell's right-hand mirror tracing scores $\left(\log _{10}\right.$ transformed) as a function of day and trial. The scores indicate steady improvement (faster latency to completion) across days and retention of learning after a 48-hr delay (day 5).

tion of the skill. Of the six trials completed on day 5, five have latencies that are well below Boswell's best performance on either day 1 or day 2 . Consistent with results from the rotor pursuit task, these findings indicate that Boswell can acquire and retain a motor skill.

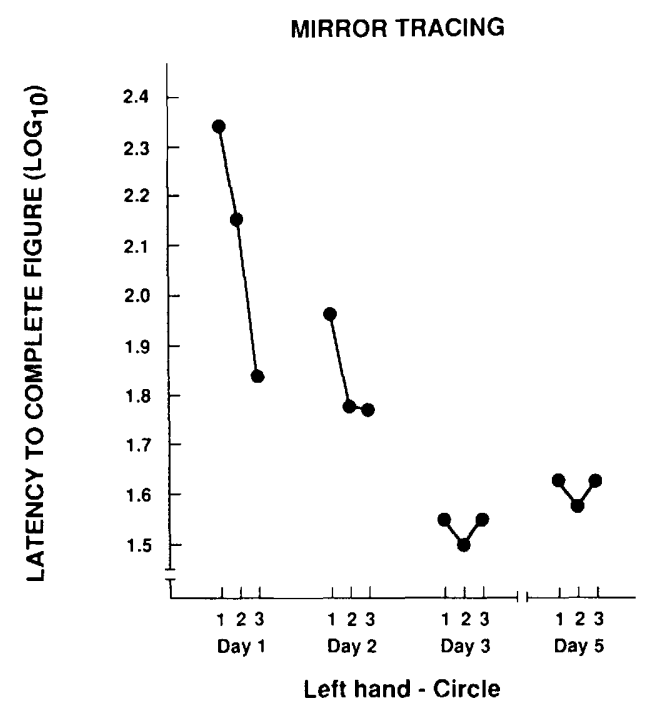

Figure 4: Boswell's left-hand mirror tracing scores ( $\log _{10}$ transformed) as a function of day and trial. The scores indicate steady improvement (faster latency to completion) across days and retention of learning after a 48-hr delay (day 5).

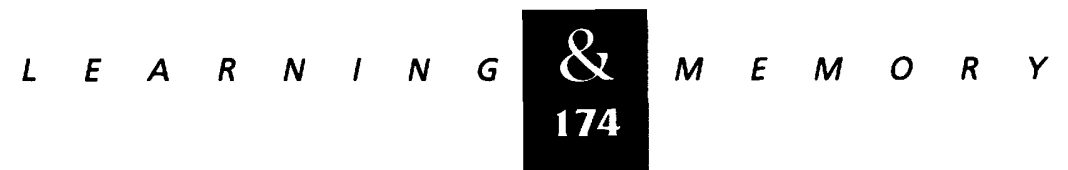


MIRROR READING

To reduce the heterogeneity of variance of the latency data, the mirror reading times were transformed to base-10 logarithms, following the data quantification format utilized by Martone et al. (1984) for similar data. These transformations are plotted in Figure 5 as a function of day and type of item (Unique vs. Repeated). The three blocks are averaged for each day, so that for each type of item, there is one data point per day.

The data in Figure 5 were analyzed with a 2 (type of item: Unique vs. Repeated) $\times 5$ (day) ANOVA. The analysis yielded significant main effects for both type $[F(1290)=5.01, P<0.05]$ and day $[F(4290)=8.39, P<0.001]$, with no interaction $(P=0.39)$. The results support the conclusions that (1) Boswell showed significant acquisition of the mirror reading skill, as a function of practice, and good retention of the skill over a 48-hour delay, and (2) Boswell showed superior acquisition of mirror reading of the repeated items, thus demonstrating sensitivity to the manipulation of exposure frequency.

On the recognition memory test, Boswell circled 16 items, 6 of which were correct (previously seen words) and 10 of which were incorrect (novel words). Using a formula that corrects for false alarms in this type of task (number of correct hits minus number of false alarms, divided by 1 minus the number of false alarms; see Wetzel and

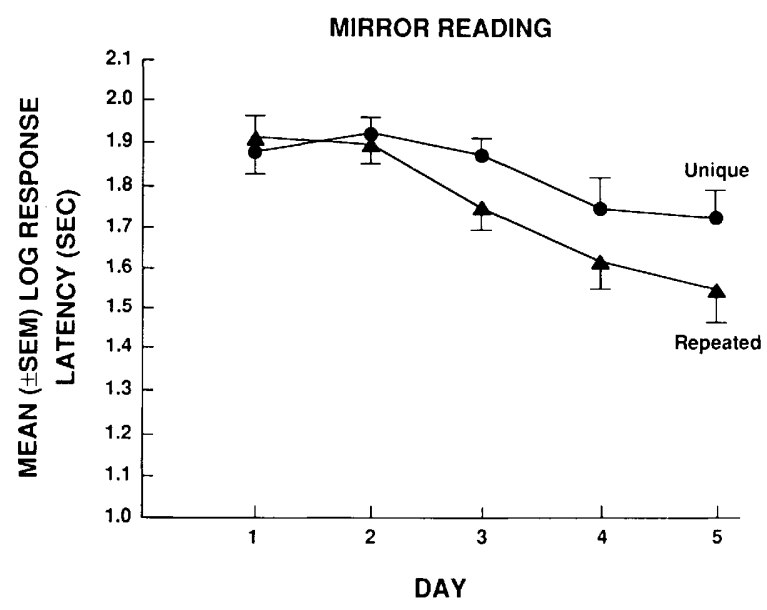

Figure 5: Boswell's mirror reading scores ( $\log _{10}$ transformed; bars indicate S.E.M.) as a function of day and type. The graph shows the pattern typically observed in normals, with steady improvement (faster reading latencies) across days, and better performance with the Repeated items.
Squire 1980), Boswell's score was $44.4 \%$, which does not differ from chance $(50 \%)$. Thus, there is no indication that Boswell learned the words to which he had been exposed during the mirror reading task; that is, his learning of the declarative information in the task was, as expected, profoundly impaired. (Interestingly, five of the six correct responses were Repeated words. There are not enough correct responses here to draw any firm conclusions, but this outcome hints that Boswell had some sensitivity to the factor of Repeated vs. Unique).

By way of additional observations, it should be noted that at no point during any of the three skill learning tasks did Boswell indicate that he remembered anything about the tasks or procedures. He never appeared to recognize having performed the tasks before. He had to be fully reinstructed prior to each trial, throughout all trials of the different tasks. His learning of declarative and context-dependent (explicit) aspects of the procedures was, to all appearances, nonexistent.

\section{Discussion}

We have shown that the capacity to acquire and retain new sensorimotor skills is spared in patients with amnesia for declarative knowledge caused by damage to mesial temporal lobe or basal forebrain structures and in the densely amnesic patient Boswell, with damage in those structures and beyond. These findings are consistent with previous work, which has demonstrated preserved skill learning in several different types of amnesic patient populations (Milner 1972; Cohen and Squire 1980; Eslinger and Damasio 1986; Butters and Stuss 1989; Damasio et al. 1989; Ewert et al. 1989; Heindel et al. 1989; Bondi and Kaszniak 1991; Gabrieli et al. 1993). Our study builds on this work in the following respects: (1) It provides evidence, for the first time, that skill learning is normal in basal forebrain amnesics; (2) it shows that patient Boswell has normal learning and long. term retention of sensorimotor skills, in spite of his extensive damage; and (3) it offers additional evidence that mesial temporal lobe damage spares skill learning.

A recent study by Gabrieli et al. (1993) demonstrated that patient H.M., who has a dense anterograde amnesia for declarative information comparable to our patient Boswell, can acquire and retain a motor skill for up to 1 year. Our study supports this finding and demonstrates that skill

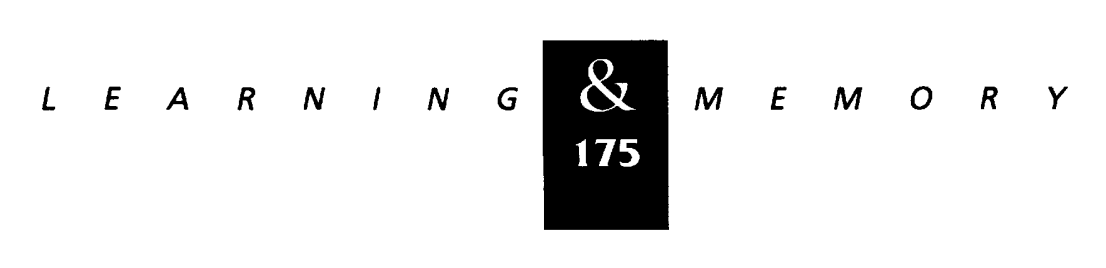


learning can be retained for a period of at least 2 years.

Why do the amnesic patients succeed on sensorimotor learning tasks? One answer to this question can be found in the nature of the demands placed on the brain by declarative and nondeclar. ative tasks. The kind of knowledge classified as declarative requires, as a necessary part of the output, an internal, topographically organized sensory representation, that is, an image. Nondeclarative motor skills rely on an external motor act. Furthermore, the motor act does not require a conscious sensory representation to guide its structuring. This is true of normals as well as of Boswell and the other amnesics. We perform certain types of motor tasks without requiring, beyond the learning period, any conscious sensory guidance (such guidance often interferes with the highly economic and automated process of well-learned motor skills). What we do learn and may recall, however, are the circumstances in which we acquired the motor skill, the "source" of the knowledge, the episodes of which motor learning was a part (cf. Schacter et al. 1984; Shimamura and Squire 1987). The contrast between source knowledge and knowledge of motor skills is especially vivid in Boswell because the declarative information that ought to have been learned and recalled together with the motor information is never acquired and subsequently is never available to him.

It should be pointed out that the study of memory always depends on motor responses of some sort, for example, pointing, verbal narratives, single word naming, completing word stems, eye movements, autonomic responses, or performance of a motor task as discussed above. The difference among those responses is in the level of consciousness required to organize them, which is almost the same as saying that the difference resides with the level of sensory guidance required to organize the response (see Damasio and Damasio 1994). At one end of the spectrum, no sensory guidance whatsoever is needed, for example, skin conductance responses, which have been utilized to demonstrate preserved but consciously inaccessible memorial information in patients with agnosia and amnesia. Such responses are the result of an autonomic motor process and are initiated by a sensory process that does not "shape the form of the response". The response is triggered, and it is there or not there, although its magnitude can vary (cf. Tranel and Damasio 1985, 1988). The same applies to responses that occur in conditioning paradigms (see Thompson 1990). In contrast, verbal testimony can only be organized on the basis of a conscious sensory representation. The same is true of a motor response that is given to describe a shape, for example, a gesture describing the shape of a fruit or animal or object. The motor responses required in skill learning tasks, on the other hand, can be guided by nonconscious dispositional representations. In short, the preservation of motor skill learning in Boswell is a consequence of the patent existence of a highly automated system capable of learning, recording, and executing motor routines.

Another perspective on the question of why Boswell and other amnesics succeed on sensorimotor skill learning tasks pertains to the brain structures required for such learning. We suggest that this learning depends on a system that includes, in the very least, the primary motor (MI) and somatosensory (SI and SII) regions, the supplementary motor area (SMA or MII), and the neostriatum, motor thalamus, and cerebellum. Substantial damage to any of these components ought to result in impairments of skill learning, and several studies have provided some evidence for the involvement of the neostriatum and cerebellum in motor learning (McCormick and Thompson 1984; Seitz et al. 1990; Grafton et al. 1992; Granholm et al. 1993).

The current findings are consistent with this notion, inasmuch as MI, MII, SI, SII, and the neostriatum, thalamus, and cerebellum are intact in Boswell and the other amnesics. Boswell's acquisition and retention of skill learning cannot depend on mesial temporal structures or the basal forebrain, because they are entirely damaged, bilaterally. Boswell's performance indicates that skill learning is spared even when there is combined damage to temporal lobe and basal forebrain. The findings from the other amnesic patients are also consistent with this notion, because none has damage to the striatal-cerebellar or sensorimotor systems, although all have damage to either the mesial temporal region or basal forebrain. Petri and Mishkin (1994) have outlined a similar position, noting that the mesial temporal/basal forebrain memory system is dedicated to declarative (explicit) knowledge, whereas the striatum and cerebellum form part of what is termed a "noncognitive habit system" of memory, that is, a system dedicated to the learning of habits, motor skills, basic conditioning, and other types of nondeclarative knowledge (see also Tranel and Damasio 1993).

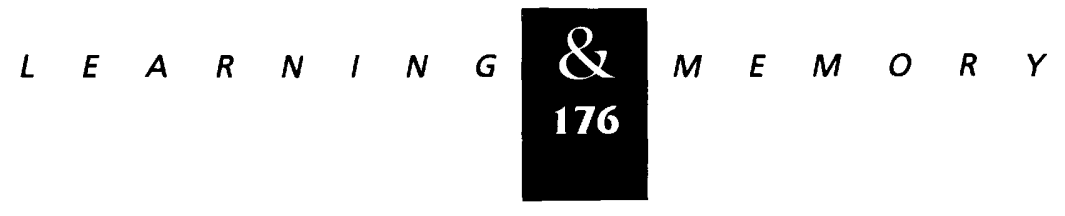


In summary, our results support the distinction between declarative and nondeclarative memory, cognitively and neurally. Additional evidence for this distinction would come from encountering a double dissociation-that is, finding that damage to the neostriatum or cerebellum impaired sensorimotor skill learning but left intact learning of declarative knowledge. There is preliminary evidence of this type in recent studies of patients with either Parkinson's disease or Huntington's disease (Flowers 1978; Heindel et al. 1988, 1989, 1993; Saint-Cyr et al. 1988; Harrington et al. 1990; Pascual-Leone et al. 1993), focal cerebellar lesions or cerebellar atrophy (Sanes et al. 1990; Fiez et al. 1992), and AIDSrelated dementia (Jones and Tranel 1991).

\section{Acknowledgment}

This work was supported by NINDS Program Project grant 19632. We thank Kathleen Welsh, Ph.D., for assistance with data collection.

The publication costs of this article were defrayed in part by payment of page charges. This article must therefore be hereby marked "advertisement" in accordance with 18 USC section 1734 solely to indicate this fact.

\section{References}

Baddeley, A. 1982. Implications of neuropsychological evidence for theories of normal memory. Philos. Trans. R. Soc. Lond. 298: 59-72.

Bondi, M.W. and A.W. Kaszniak. 1991. Implicit and explicit memory in Alzheimer's disease and Parkinson's disease. ). Clin. Exp. Neuropsychol. 13: 339-358.

Butters, N. and D.T. Stuss. 1989. Diencephalic amnesia. In Handbook of neuropsychology, Vol. 3 (ed. F. Boller and J. Grafman), pp. 107-148. Elsevier, Amsterdam, Netherlands.

Cermak, L.S., R. Lewis, N. Butters, and H. Goodglass. 1973. Role of verbal mediation in performance of motor tasks by Korsakoff patients. Percep. Motor Skills 37: 259-262.

Cohen, N.J. and H. Eichenbaum. 1993. Memory, amnesia, and the hippocampal system. MIT Press, Cambridge, MA.

Cohen, N.J. and L.R. Squire. 1980. Preserved learning and retention of pattern-analyzing skill in amnesia: Dissociation of knowing how and knowing that. Science 210: 207-210.

Corkin, S. 1965. Tactually-guided maze learning in man: Effects of unilateral cortical excisions and bilateral hippocampal lesions. Neuropsychologia 3: 339-351.

1968. Acquisition of motor skill after bilateral medial temporal-lobe excision. Neuropsychologia 6: 255-265.
Damasio, A.R. 1989. Time-locked multiregional retroactivation: A systems level proposal for the neural substrates of recall and recognition. Cognition 33: 25-62.

Damasio, A.R. and H. Damasio. 1994. Cortical systems for retrieval of concrete knowledge: The convergence zone framework. In Large-scale neuronal theories of the brain (ed. C. Koch and J.L. Davis), pp. 61-74. MIT Press, Cambridge, MA.

Damasio, A.R., H. Damasio, D. Tranel, K. Welsh, and J. Brandt. 1987. Additional neural and cognitive evidence in patient DRB. Soc. Neurosci. 13: 1452.

Damasio, A.R., N.R. Graff-Radford, P.J. Eslinger, H. Damasio, and N. Kassell. 1985a. Amnesia following basal forebrain lesions. Arch. Neurol. 42: 263-271.

Damasio A.R., P.J. Eslinger, H. Damasio, G.W. Van Hoesen, and S. Cornell. 1985b. Multimodal amnesic syndrome following bilateral temporal and basal forebrain damage. Arch. Neurol. 42: 252-259.

Damasio, A.R., D. Tranel, and H. Damasio. 1989. Amnesia caused by herpes simplex encephalitis, infarctions in basal forebrain, Alzheimer's disease, and anoxia. In Handbook of neuropsychology, Vol. 3 (ed. F. Boller and J. Grafman), pp. 149-166. Elsevier, Amsterdam, Netherlands.

Damasio, H. and A.R. Damasio. 1989. Lesion analysis in neuropsychology. Oxford University Press, New York.

Damasio, H. and R. Frank. 1992. Three-dimensional in vivo mapping of brain lesions in humans. Arch. Neurol. 49: 137-143.

Daum, I., H. Ackermann, M.M. Schugens, C. Reimold, J. Dichgans, and N. Birbaumer. 1993. The cerebellum and cognitive functions in humans. Behav. Neurosci. 107: 411-419.

Eslinger, P.J. and A.R. Damasio. 1986. Preserved motor learning in Alzheimer's disease: Implications for anatomy and behavior. J. Neurosci. 6: 3006-3009.

Ewert, J., H.S. Levin, M.G. Watson, and Z. Kalisky. 1989. Procedural memory during posttraumatic amnesia in survivors of severe closed head injury. Arch. Neurol. 46: $911-916$.

Fiez, J.A., S.E. Petersen, M.K. Cheney, and M.E. Raichle. 1992. Impaired non-motor learning and error detection associated with cerebellar damage. Brain 115: 155-178.

Flowers, K. 1978. Some frequency response characteristics of parkinsonism on pursuit tracking. Brain 101: 19-34.

Gabrieli, J.D.E., S. Corkin, S.F. Mickel, and J.H. Growdon. 1993. Intact acquisition and long-term retention of mirror-tracing skill in Alzheimer's disease and in global amnesia. Behav. Neurosci. 107: 899-910. 


\section{Tranel et al.}

Grafman, J., I. Litvan, S. Massaquoi, M. Stewart, A. Sirigu, and $M$. Hallett. 1992. Cognitive planning deficit in patients with cerebellar atrophy. Neurology 42: 1493-1496.

Grafton, S.T., J.C. Mazziotta, S. Presty, K.J. Friston, R.S. Frackowiak, and M.E. Phelps. 1992. Functional anatomy of human procedural learning determined with regional cerebral blood flow and PET. J. Neurosci. 12: 2542-2548.

Granholm, E., G. Bartzokis, R.F. Asarnow, and S.R. Marder. 1993. Preliminary associations between motor procedural learning, basal ganglia $\mathrm{T} 2$ relaxation times, and tardive dyskinesia in schizophrenia. Psychiat. Res. 50: 33-44.

Harrington, D.L., K.Y. Haaland, R.A. Yeo, and E. Marder. 1990. Procedural memory in Parkinson's disease: Impaired motor but not visuoperceptual learning. J. Clin. Exp.

Neuropsychol. 12: 323-339.

Heindel, W.C., N. Butters, and D.P. Salmon. 1988. Impaired learning of a motor skill in patients with Huntington's disease. Behav. Neurosci. 102: 141-147.

Heindel, W.C., D.P. Salmon, C.W. Shults, P.A. Walicke, and N. Butters. 1989. Neuropsychological evidence for multiple implicit memory systems: A comparison of Alzheimer's, Huntington's, and Parkinson's disease patients. J. Neurosci. 9: 582-587.

Heindel, W.C., D.P. Salmon, and N. Butters. 1993. Cognitive approaches to the memory disorders of demented patients. In Comprehensive handbook of psychopathology, 2nd ed. (ed. P.B. Sutker and H.E. Adams), pp. 735-761. Plenum, New York.

Hintzman, D.L. 1990. Human learning and memory: Connections and dissociations. Annu. Rev. Psychol. 41: 109-139.

Jones, R.D. and D. Tranel. 1991. Preservation of procedural memory in HIV-positive patients with "subcortical" dementia. J. Clin. Exp. Neuropsychol. 13: 74.

Klucznik, R.P., D.A. Carrier, R. Pyka, and R.W. Haid. 1993. Placement of a ferromagnetic intracerebral aneurysm clip in a magnetic field with a fatal outcome. Radiology 187: 855-856.

Lezak, M.D. 1983. Neuropsychological assessment, 2nd ed. Oxford University Press, New York.

Martone, M., N. Butters, M. Payne, J. Becker, and D. Sax. 1984. Dissociations between skill learning and verbal recognition in amnesia and dementia. Arch. Neurol. 41: 965-970.

McCormick, D.A. and R.F. Thompson. 1984. Cerebellum: Essential involvement in the classically conditioned eyelid response. Science 223: 296-299.

Milner, B. 1962. Les troubles de la memoire accompagnant des lesions hippocampiques bilaterales. In Physiologie de
I'hippocampe, pp 257-272. Centre National de la Recherche Scientifique, Paris, France.

1972. Disorders of learning and memory after temporal lobe lesions in man. Clin. Neurosurg. 19: 421-446.

Pascual-Leone, A., J. Grafman, K. Clark, M. Stewart, S. Massaquoi, J.-S. Lou, and M. Hallett. 1993. Procedural learning in Parkinson's Disease and cerebellar degeneration. Ann. Neurol. 34: 594-602.

Petri, H.L. and M. Mishkin. 1994. Behaviorism, cognitivism and the neuropsychology of memory. Am. Sci. 82: 30-37.

Saint-Cyr, J.A., A.E. Taylor, and A.E. Lang. 1988. Procedural learning and neostriatal dysfunction in man. Brain 111: 941-959.

Saint-Cyr, J.A. and A.E. Taylor. 1992. The mobilization of procedural learning: The "key signature" of the basal ganglia. In Neuropsychology of memory, 2nd ed. (ed. L.R. Squire and N. Butters), pp. 188-202. The Guilford Press, New York.

Sanes, J.N., B. Dimitrov, and M. Hallett. 1990. Motor learning in patients with cerebellar dysfunction. Brain 113: $103-120$.

Schacter, D.L. 1987. Implicit memory: History and current status. J. Exp. Psychol.: Learn. Mem. Cognition 13: 501-518.

Schacter, D., J.L. Harbluk, and D.R. McLachlan. 1984. Retrieval without recollection: An experimental analysis of source amnesia. I. Verbal Learn. Verbal Behav. 23: 593-611.

Schmahmann, J.D. 1991. An emerging concept: The cerebellar contribution to higher function. Arch. Neurol. 48: $1178-1187$.

Seitz, R.J., P.E. Roland, C. Bohm, T. Greitz, and S. Stone-Elander. 1990. Motor learning in man: A positron emission tomographic study. NeuroReport 1: 57-66.

Shimamura, A.P. 1990. Forms of memory: Issues and directions. In Brain organization and memory: Cells, systems, and circuits (ed. J.L. McGaugh, N.M. Weinberger, and G. Lynch), pp. 159-173. Oxford University Press, New York.

Shimamura, A.P. and L.R. Squire. 1987. A neuropsychological study of fact memory and source amnesia. J. Exp. Psychol.: Learn. Mem. Cognition 13: $464-473$.

Spreen, O. and E. Strauss. 1991. A compendium of neuropsychological tests. Oxford University Press, New York.

Squire, L.R. 1992. Memory and the hippocampus: A synthesis from findings with rats, monkeys, and humans. Psychol. Rev. 99: 195-231.

Thompson, R.F. 1986. The neurobiology of learning and memory. Science 233: 941-947.

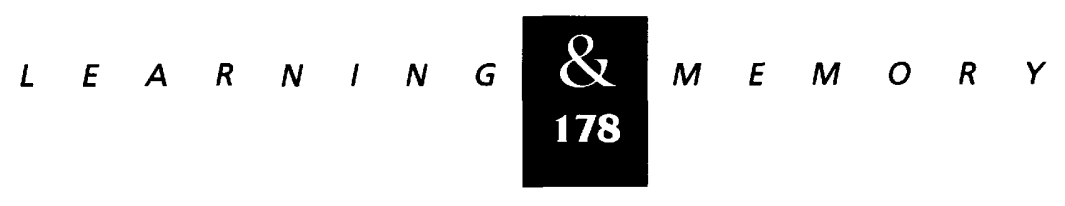


1990. Neural mechanisms of classical conditioning in mammals. Phil. Trans. R. Soc. Lond. B 329: 161-170.

Tranel, D. 1994. The lowa-Benton school of neuropsychological assessment. In Neuropsychological assessment of neuropsychiatric disorders, 2nd ed. (ed. I. Grant and K.M. Adams). Oxford University Press, New York. (In press.)

Tranel, D. and A.R. Damasio. 1985. Knowledge without awareness: An autonomic index of facial recognition by prosopagnosics. Science 228: 1453-1454.

1988. Nonconscious face recognition in patients with face agnosia. Behav. Brain Res. 30: 235-249.

1993. The covert learning of affective valence does not require structures in hippocampal system or amygdala. $/$. Cog. Neurosci. 5: 79-88.

Wetzel, C. D. and L.R. Squire. 1980. Encoding in anterograde amnesia. Neuropsychologia 18: 177-184.

Received July 22, 1994; accepted in revised form September 9, 1994. 


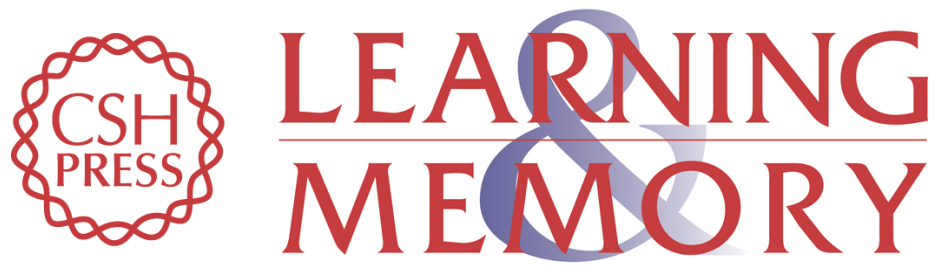

\section{Sensorimotor skill learning in amnesia: additional evidence for the neural basis of nondeclarative memory.}

D Tranel, A R Damasio, H Damasio, et al.

Learn. Mem. 1994, 1:

Access the most recent version at doi:10.1101//m.1.3.165

References This article cites 45 articles, 8 of which can be accessed free at: http://learnmem.cshlp.org/content/1/3/165.full.html\#ref-list-1

License

Email Alerting Receive free email alerts when new articles cite this article - sign up in the box at the Service top right corner of the article or click here. 